\title{
Does Intradialytic Group Exercise Influence Malnutrition and Quality of Life in Maintenance Hemodialysis Patients? Evidence From an Experimental Study Using a Single-group Repeated- measures Design
}

\section{Li-Juan Zhou}

Hospital Affiliated 5 to Nantong University(Taizhou People's Hospital)

\section{Li-Yuan Zhang}

Hospital Affiliated 5 to Nantong University(Taizhou People's Hospital)

Dan Shi ( $\sim$ shidan20210817@126.com )

Hospital Affiliated 5 to Nantong University(Taizhou People's Hospital)

Qian Wang

Hospital Affiliated 5 to Nantong University(Taizhou People's Hospital)

\section{Li Chen}

Hospital Affiliated 5 to Nantong University(Taizhou People's Hospital)

\section{Research Article}

Keywords: renal dialysis, group exercise, aerobic exercise, resistance exercise nutrition, quality of life, REPEATED measures design

Posted Date: November 10th, 2021

DOI: https://doi.org/10.21203/rs.3.rs-939540/v1

License: (c) (i) This work is licensed under a Creative Commons Attribution 4.0 International License. Read Full License 


\section{Abstract}

\section{Background}

Maintenance hemodialysis (MHD) patients is the representative of the sedentary group and often suffer from physical inactivity. Exercise rehabilitation is not widely included in dialysis care despite demonstrated health benefits. This study aimed to evaluate the effectiveness of intradialytic group exercise in MHD patients.

\section{Methods}

This was a single center, single-group repeated-measures design study, which included MHD patients in the hemodialysis center in Taizhou, China. The 12-week, 3 times per week intradialytic group exercise programme was conducted around 30 min during the first 2 hours of each dialysis session. Anthropometric indicators, including Body Mass Index (BMI), Triceps Skinfold Thickness (TSF), Mid-upper Arm Circumference (MUAC), Mid-arm Muscle Circumference (MAMC) Handgrip Strength (HGS), and quality of life were measured at baseline, 4-week follow up and 12-week follow up. Laboratory indicators, including Hemoglobin level ( $\mathrm{Hb}$ ), Total Protein (TP) and Albumin (Alb) were measured at baseline and 12week follow up. The repeated-measures analysis of variance and Friedman test were used to compare the parametric and non-parametric data at three time points, respectively. Paired t test was used to compare the continuous parametric between two time points.

Results

Ninety patients were enrolled at baseline and seventy-five patients finished the whole 12-week exercise programme. There were 7 patients dropped out for losing of motivation and sample churn rate for losing of motivation was $7.8 \%$ (7/90). Participants reported significant improvements in most of the outcomes, $\operatorname{TSF}(F(2,148)=28.908, p=0.000), \operatorname{MUMC}(F(2,148)=3.1821, p=0.044), \operatorname{MAMC}(F(2,148)=27.795, p$ $=0.000), \operatorname{HGS}(F(2,148)=42.383, p=0.000), \operatorname{TP}(F(t=-2.417, p=0.018), \operatorname{ALB}(t-3.190, p=0.002), \mathrm{Hb}(t$ $=-2.353, p=0.021)$, and QOL $(F(2,148)=10.48, p=0.000)$.

\section{Conclusions}

The positive results from this research suggest that intradialytic group exercise programme including aerobic exercise and resistance exercise is a safe and suitable exercise way for maintenance hemodialysis patients. This exercise can help keep patients' motivation and improve nutritional status and quality of life in maintenance hemodialysis patients.

\section{Background}

Chronic kidney disease (CKD) has become a leading public health problem in the past decade[1] and it gains a high prevalence in developing countries. End-stage renal disease (ESRD) is a major lethal factor in patients with CKD. ESRD is incurable unless it is managed by a renal transplantation. For the lack of 
renal graft, lifelong dialysis has been the main treatment for most ESRD patients. In China, maintenance hemodialysis (MHD) is the most widely used therapeutic approach for the treatment of ESRD, the number of MHD patients reached to 710,000 in 2019[2]. Due to anemia, comorbid diseases (such as cardiovascular and pulmonary diseases, infection and diabetes mellitus), malnutrition, consequences of renal failure per se (such as abnormal muscle ultrastructure, mitochondrial dysfunction and fluid and electrolyte), and physical deconditioning, MHD patients become the representative of the sedentary group and often suffer from physical inactivity $[3,4]$, which subsequently result in impaired exercise capacity, ultimately muscle wasting, an increased risk of hospitalization and mortality and a poor quality of life (QOL)[4-7].

Given the fact that low physical activity is prevalent and harmful, the Kidney Disease Outcomes Quality Initiative Clinical Practice Guidelines recommend all dialysis patients to increase their level of physical activity[8]. The whole nephrology staffs are also encouraged to help patients engage in it[9]. Exercise training, as a type of physical activity, has been shown great benefits for MHD patients. Suitable and regular exercise can improve their physical function, nutritional status, psychological status, survival rate and QOL[10-13].

Based on the exercise time, exercise training in MHD patients can be divided into intradialytic exercise and extradialytic exercise. Intradialytic exercise is superior to interdialytic exercise in patient adherence and medical staffs' supervision[14,15]. Exercise training can be subdivided into three major types based on the exercise type, including aerobic exercise, resistance exercise and a combination of above two types. All these three types of exercise have been confirmed the safety and effectiveness of exercise training in MHD patients[13, 16]. Although exercise training has received increasing attention in MHD patients, it remains a neglected aspect of dialysis care. There are many barriers to encourage both patients and health professionals to increase the level of physical activity of dialysis patients[8, 12]. Among which, the lack of exercise-related knowledge, the fear of injuries and the lack of motivation are the common barriers from the patients' perspective, and resources restrictions are the major ones from the perspectives of health providers[17].

Group exercise is a type of exercise, which means a group of people with some common characteristics do exercise together. The social interaction and sense of belonging involved in it have been proved to have a positive effect on motivation and adherence to the interventions[18, 19]. Moreover, group exercise provides a resource-saved way of exercise training, because several patients get together and exercise under the supervision of the same health professionals. So, this way of exercise training has two-way benefits for patients and caregivers. Dialysis units can be sociable and are suitable for the conduct of group exercise[20,21]. This exercise may allow individuals with MHD patients to maintain and increase their level of physical activity. To our knowledge, the effects of intradialytic group exercise in MHD patients are not clear. Thus, the aim of our study was to examine the effects of a 12-week intradialytic group exercise programme on the malnutrition and QOL in MHD patients.

\section{Methods}




\section{Study design}

The 12-week study applied a repeated measure research design. The study was registered in the Chinese Clinical Trial Registry (ChiCTR2000034394), and was conducted according to the Declaration of Helsinki and approved by the Ethics Committee of Taizhou People's Hospital, China (KY 202004001). All participants gave informed consent before participation.

\section{Participants}

A total of 178 MHD patients, who took regular maintenance hemodialysis in the Hemopurification Center, the Taizhou People's Hospital from May to June 2020, were available for enrollment. The study included participants who (1) were 18 years of age or older, (2) had been receiving hemodialysis treatment for more than 3 months, (3) took hemodialysis 4 hours per time and 3 times per week (Monday-WednesdayFriday or Tuesday-Thursday-Saturday), (4) had no physical disability and both upper and lower muscle strength were not less than grade III, (5) could communicate normally, and (6) were willing to take part in the study and gave informed consent. The excluded criteria were as follows: (1) had serious complications such as uncontrolled cardiovascular disease, malignant tumors, serious infection, and active bleeding, (2) lost exercise motivation, and (3) unable to finish the whole exercise programme, such as taking a surgery, hospitalization, being dead or transferring to another blood purification center. Among the 178 MHD patients, 90 patients were recruited at the baseline and 75 patients finish the whole exercise programme. The flow chart of patients during the study is shown in Fig.1.

\section{Intervention}

The Hemopurification Center is divided into10 wards, with 4 to 10 beds in each. The center staff assigned the participations, with good relationships and under the same purification time, into the same ward and these patients were seen as a group. After then, the purification bed was fixed unless the patients wanted a change.

The 12-week, 3times per week intradialytic group exercise programme was conducted around 30 min during the first 2 hours $[4,22,23]$ of each hemodialysis session, and consisted of aerobic exercise and resistance exercise. Before the purification started, the participations would take a 5-minite warm up exercise by muscle stretching. After starting the exercise, the patients remained lying on the bed until the end of the purification treatment. A polite study was conducted to determine the feasibility and safety of the exercise protocol.

Aerobic exercise was firstly performed in the upper limb without arteriovenous fistula, including fist clenching-relaxing movements, wrist forward-reverse rotation movements and elbow extension-flexion movements. Then, aerobic exercise was performed in both lower limbs, including ankle forward-reverse rotation movements, keen extension-flexion movements and leg raising movements. Four sets of 8 repetitions of each movement were performed. 
Resistance loop bands (PROIRON®, SHANXI REGENT, China) were applied in the resistance exercise. These bands had 5 tension levels, including X-Light (5-10lbs), Light (15-20lbs), Medium (25-30lbs), Heavy (35-40lbs), and X-Heavy (45-50lbs). The tension levels were set according to the MHD patients' tolerance every time before the exercise conduction. During the resistance exercise, the patient could reduce the tension level by changing the resistance band or take a rest if $\mathrm{s} /$ he reported the Rating of Perceived Exertion (RPE)[24] was over 15 points[16]. Resistance exercise was divided into upper limb training and lower limb training. Upper limb training: (1) equip the loop band with 2 cushioned handles and lie on the dialysis bed; (2) step on a cushioned handle with the foot arch of the non-dialysis side and hold the other cushioned handle firmly by the non-dialysis upper limb, with the palm side up and upper arm fixed; (3) do elbow extension-flexion movements and try to bring the fist close to the chest; (4) perform 10 sets of 10 repetitions and take a 10-second-rest between every two sets. Lower limb training: (1) straight-leg-raising movements: circle the loop band around the ankles of both feet; take turns to raise both feet as high as the patient can; hold for 1 second before slowly lower the foot above; perform 5 sets of 10 repetitions and take a 10-second-rest between every two sets. (2) clamshell exercise: loop a band around both thighs, just above the knees; lie on the side without arteriovenous fistula and hips stacked, knees bent 90 degrees, and head resting on the non-dialysis arm; draw the knees in toward the body and make sure the feet are in line with the butt; place the hand with arteriovenous fistula on the hip; Keeping feet together, raise the above knee as far as the patient can without rotating the hip or lifting the knee below off the bed; hold for 1 second before slowly lower the above knee; perform 5 sets of 10 repetitions and take a 10-second-rest between every two sets.

Actions were taken to guarantee the safety of MHD patients. Before the exercise training, patients with following situations were forbidden to exercise: (1) abnormal vital signs (blood pressure $>200 / 100 \mathrm{mmHg}$ or $<110 / 50 \mathrm{mmHg}$, heart rate per minute< 60 , and oxygen saturation< $80 \%$ ); (2) interdialytic weight gain $($ IDWG $)>5 \%$. And during the exercise, a continuous supervision of blood pressure, heart rate, and oxygen

saturation was conducted. Patients should stop their exercise immediately when (1) their blood pressure were $>200 / 100 \mathrm{mmHg}$ or $<110 / 50 \mathrm{mmHg}$; (2) their heart rate were over $80 \%$ of the maximum heart rate (maximum heart rate = 220-age); (3) they had hypoglycemia, dizziness, headache, pale complexion, chest pain, dyspnea, and etc.

\section{Outcome measurements and tools}

Anthropometric indicators: All the following nutritional anthropometric indicators were measured for 3 times during the study (baseline, 4 weeks and 12 weeks). (1) Body Mass Index (BMI): the BMI was calculated as weight/height ${ }^{2}\left(\mathrm{~kg} / \mathrm{m}^{2}\right)$ and according to $\mathrm{BMI}$, the weight could be divided into underweight $\left(\mathrm{BMl}<18.5 \mathrm{~kg} / \mathrm{m}^{2}\right)$, normal weight $\left(18.5 \mathrm{~kg} / \mathrm{m}^{2} £ \mathrm{BMl}<25 \mathrm{~kg} / \mathrm{m}^{2}\right)$, overweight $\left(25 \mathrm{~kg} / \mathrm{m}^{2} £ \mathrm{BMl}<30 \mathrm{~kg} / \mathrm{m}^{2}\right)$, obesity (BMI $330 \mathrm{~kg} / \mathrm{m}^{2}$ )[25]. (2) Triceps Skinfold Thickness (TSF): TSF was measured using skinfold calipers and the needle was read to the nearest $0.5 \mathrm{~mm}$. The measurement point was at the midpoint between the olecranon and the acromion tip[26] of the non-dialysis arm. The averages of two consecutive measurements were recorded. (3) Mid-upper Arm Circumference (MUAC): MUAC was measured in the 
non-dialysis side by a tape ruler at the midpoint of upper arm with the arm dropping naturally. Results were recorded to the nearest $0.1 \mathrm{~cm}$ and the averages of two consecutive measurements were recorded. (4) Mid-arm Muscle Circumference (MAMC): the MAMC was calculated as (MUAC - 3.14*TSF)[27]. (5) Handgrip Strength (HGS)[28]: The HGS of the non-dialysis hand was measured by an electronic hand dynamometer $\left(\mathrm{KYTO}{ }^{\circledR}\right.$, Dongguan, Guangdong, China) before the start of dialysis treatment. Results were recorded to the nearest $0.1 \mathrm{~kg}$ and the larger of two consecutive measurements were recorded.

Laboratory indicators: Laboratory tests were done in baseline and 12 weeks after the conduction of the exercise programme. Blood sampling was performed after an overnight fast on dialysis-free days and samples were analyzed in laboratory of Taizhou People's Hospital. Hemoglobin level $(\mathrm{Hb})$ was analyzed on a hematology analyzer (XN-20, sysmex ${ }^{\circledR}$, Kobe-shi, Japan). Total protein (TP) and albumin (Alb) were analyzed on a bio analysis machine (AU5800, Beckman Coulter, Shanghai, China)

Chinese version kidney disease quality of life-short form (KDQL-SF ${ }^{m}$, Version 1.3): The KDQL-SF consists of a 36-item short form health survey (SF-36) and a 12-filed survey in kidney disease-targeted areas (KDTA). The Chinese version of KDQL-SF ${ }^{\mathrm{TM}}$ demonstrates good reliability, with the good internal consistency (Cronbach's alpha ranging from 0.69-0.78) and test-retest reliability (ranging from 0.70 to $0.86)[29]$. The reliability of this instrument is good, with the support of good convergent validity and known-group validity[29]. Scores of KDQL were calculated according to the manual for use and scoring[30]. The scores range from 0 to 100 , and the higher the KDQOL-36 ${ }^{\mathrm{TM}}$ score, the better QOL the patients have[17].

\section{Statistical analysis}

Data analysis was carried out using SPSS 22.0 (IBM, Armonk, NY, USA). Results were demonstrated as means and standard deviation (SD), count and percentages, and medians and Quartile (Q25 - Q75). The repeated-measures analysis of variance and Friedman test were used to compare the parametric and non-parametric data at three time points, respectively. Paired $t$ test was used to compare the continuous parametric between two time points. All statistical tests were two-tailed, and $P<0.05$ was considered statistically significant. Cohen's d effect size was calculated at 12 weeks post-intervention. Effect size were divided into small $(d=0.02)$, medium $(d=0.50)$, and large $(d=0.80)$.

\section{Results}

\section{Demographic and clinical characteristics}

A total of 75 MHD patients (35 males) finished the whole 12-week intradialytic group exercise. The mean age of the participants was 55.03 (10.69) years, ranged from 25 to 77 years. The majority of participants were married (92.0\%), and were with no religious belief (84.0\%). More than half people (68\%) had the duration on dialysis longer than 36 months. The details of demographic and clinical characteristics are reported in Table 1. 
Table 1 Demographic and clinical characteristics 


\begin{tabular}{|c|c|}
\hline Characteristics & $\mathrm{N}=75$ \\
\hline \multicolumn{2}{|l|}{ Age (years) } \\
\hline Mean \pm SD & $55.03 \pm 10.69$ \\
\hline \multicolumn{2}{|l|}{ Gender, n (\%) } \\
\hline Man & $35(46.7)$ \\
\hline Women & $40(53.3)$ \\
\hline \multicolumn{2}{|l|}{ Education level, n (\%) } \\
\hline Primary school education or illiteracy & $16(21.3)$ \\
\hline Secondary school or high school education & $50(66.7)$ \\
\hline College or higher education & $9(12.0)$ \\
\hline \multicolumn{2}{|l|}{ Marital status, n (\%) } \\
\hline Married & $69(92.0)$ \\
\hline Divorced, Single or Widowed & $6(8.0)$ \\
\hline \multicolumn{2}{|l|}{ Work status, n (\%) } \\
\hline Employment & $14(18.7)$ \\
\hline Resignment & $24(32.0)$ \\
\hline Retirement & $37(49.3)$ \\
\hline \multicolumn{2}{|l|}{ Religious belief, n (\%) } \\
\hline Buddhism & $10(13.3)$ \\
\hline Christianity & $2(2.7)$ \\
\hline None & $63(84.0)$ \\
\hline \multicolumn{2}{|l|}{ Payment way, n (\%) } \\
\hline Private expenses & $2(2.6)$ \\
\hline Medical insurance & $73(97.3)$ \\
\hline \multicolumn{2}{|l|}{ Average income monthly, $\mathrm{n}(\%)$} \\
\hline$£ 1000$ yuan & $35(46.7)$ \\
\hline 1001 3000 yuan & $26(34.7)$ \\
\hline $3001 \sim 5000$ yuan & $10(13.3)$ \\
\hline > 5000 yuan & $4(5.3)$ \\
\hline
\end{tabular}




\begin{tabular}{|ll|}
\hline Primary disease, $\mathrm{n}(\%)$ & \\
\hline Hypertensive renal disease & $21(28.0)$ \\
\hline Diabetic nephropathy & $37(49.3)$ \\
\hline Systemic lupus erythematosus & $9(12.0)$ \\
\hline Others & $2(2.7)$ \\
\hline Duration on dialysis (month) & $6(8.0)$ \\
\hline Median, Q25 - Q75 & $55,32-91$ \\
\hline
\end{tabular}

\section{Effects of intradialytic group exercise on malnutrition}

Performance for all the nutrition indicators along two of three evaluation times and the effect size at 12 weeks are demonstrated in Table 2. Positive results were seen in all the nutrition indicators, except the BMI.

Table 2 Nutrition indicators and QOL at baseline, 4-week and 12-week follow up 


\begin{tabular}{|c|c|c|c|c|c|c|}
\hline Indicators & Baseline & At 4 weeks & At 12 weeks & $\mathrm{c} 2 / \mathrm{F} / \mathrm{T}$ & $P$ & $\begin{array}{l}\text { Cohen's } \\
\text { d }\end{array}$ \\
\hline $\begin{array}{l}\mathrm{BMl}{ }^{\mathrm{a}}, \mathrm{n}(\%), \\
\mathrm{kg} / \mathrm{m}^{2}\end{array}$ & & & & 2.571 & 0.276 & NA \\
\hline$<18.5$ or $>25$ & $24(32.0)$ & $24(32.0)$ & $21(28.0)$ & & & \\
\hline $18.5-25$ & $51(68.0)$ & $51(68.0)$ & $54(72.0)$ & & & \\
\hline $\begin{array}{l}\text { TSF b, Mean } \pm \\
\text { SD, mm }\end{array}$ & $21.21 \pm 8.27$ & $17.86 \pm 6.86$ & $15.93 \pm 5.91$ & 28.908 & 0.000 & 0.805 \\
\hline $\begin{array}{l}\text { MUAC b, Mean } \pm \\
\text { SD, cm }\end{array}$ & $25.62 \pm 8.27$ & $20.00 \pm 3.04$ & $26.13 \pm 2.92$ & 3.181 & 0.044 & 0.233 \\
\hline $\begin{array}{l}\text { MAMC b, Mean } \pm \\
\text { SD, cm }\end{array}$ & $18.96 \pm 2.66$ & $20.43 \pm 2.57$ & $21.18 \pm 2.88$ & 27.795 & 0.000 & 0.718 \\
\hline $\begin{array}{l}\mathrm{HGS}^{\mathrm{b}} \text {, Mean } \pm \\
\text { SD, kg }\end{array}$ & $19.43 \pm 5.94$ & $24.42 \pm 6.94$ & $26.04 \pm 8.38$ & 42.383 & 0.000 & 0.874 \\
\hline $\begin{array}{l}\text { TP }{ }^{c}, \text { Mean } \pm S D \text {, } \\
g / L\end{array}$ & $75.28 \pm 7.51$ & & $77.01 \pm 6.91$ & -2.417 & 0.018 & 0.279 \\
\hline $\begin{array}{l}\text { ALB }^{c} \text {, Mean } \pm \\
\text { SD, g/L }\end{array}$ & $43.32 \pm 3.58$ & & $43.57 \pm 3.69$ & -3.190 & 0.002 & 0.368 \\
\hline $\begin{array}{l}\mathrm{Hb}^{c}{ }^{\mathrm{c}}, \text { Mean } \pm \mathrm{SD}, \\
\mathrm{g} / \mathrm{L}\end{array}$ & $106.23 \pm 20.20$ & & $109.72 \pm 20.81$ & -2.353 & 0.021 & 0.273 \\
\hline $\begin{array}{l}\text { QOL }{ }^{b}, \text { Mean } \pm \\
\text { SD }\end{array}$ & $66.07 \pm 16.02$ & $69.24 \pm 14.08$ & $73.45 \pm 12.15$ & 10.48 & 0.000 & 0.462 \\
\hline
\end{tabular}

NOTE. NA = Not appliable. ${ }^{a}$ Friedman test; ${ }^{b}$ Repeated-measures analysis of variance; ${ }^{c}$ Paired $t$ test.

\section{Effects of intradialytic group exercise on QOL}

The effect of intradialytic group exercise on QOL along the 12 week is shown in Table 2 . The exercise programme has a positive influence on QOL of MHD patients $(F(2,148)=10.48, p=0.000)$.

\section{Discussion}

As the representative of sedentary group, the MHD patients are encouraged to take more exercise[8]. Previous studies have confirmed that exercise could bring dialysis patients with better exercise capacity[3], physical function[4, 17, 31], sleep quality[4], nutritional status[31], psychological status[10], quality of life[10,31], and better hemodialysis survival[11]. Exercise ways in MHD patients can be divided into three major types, including aerobic exercise, resistance exercise and a combination of aerobic exercise and resistance exercise. Aerobic exercise, using large muscle groups, primarily improves 
oxidative capacity and cardiovascular function, so as to improve endurance. Individual aerobic exercise in MHD patients is safe and has a significant effect on the control of hypertension, physical capacity, sleep quality and QOL[32-34]. Resistance exercise is a way to increase muscle size and strength. The major effect of resistance exercise in MHD patients is improving muscle strength and physical performance, and it may help in reducing microinflammatory reactions and protein-energy wasting[16, 3540]. The combination of aerobic exercise and resistance exercise is a common paradigm in exercise prescription, which embraces advantages of these two exercise ways. As a recent systematic review showed, differences between combined exercise and aerobic or resistance exercise alone did not reach statistical significance, even though the combined one resulted in the largest effect sizes[41]. In a word, despite numerous published studies about exercise rehabilitation in MHD patients, the best exercise way has not been determined.

According to the exercise time, exercise in MHD patients can be divided into two categories: intradialytic exercise and extradialytic exercise. Intradialytic exercise, generally done during the first two hours during the hemodialysis session, aims to increase the patients' strength and endurance, and hence targeting various physiological and psychosocial parameters[34, 42]. Unlike exercise ways, the better exercise time for MHD patients has reached a consensus. Although extradialytic exercise may be better in improving exercise capacity and functional ability, intradialytic exercise shoes great superiority in better adoption, lower drop-out, and greater compliance[43-45]. Therefore, intradialytic exercise is named the nonpharmacological medicine for MHD patients[42]. Based on the previous studies about intradialytic exercise, we found that even though it could help reduce drop-out and increase compliance, the sample churn rate (not including force majeure, such as medical reasons, transfer, and hospitalization) remained in high levels, ranging from $0 \%$ to $33.3 \%$, most of which were larger than $20 \%[4,16,40,46-49]$. More methods should be found to reduce drop-out and improve compliance.

Group exercise, which has a positive effect on motivation and adherence, may help MHD patients adhere exercise programme. Most MHD patients take lifelong dialysis and they typically undergo 4-hour-long hemodialysis sessions three times a week on fixed days. As a result, MHD patients in the same hemodialysis center are always know each other well. And this provides a good base for the conduction of intradialytic group exercise. In our study, we applied an intradialytic group exercise programme in MHD patients. The 12-week, 3times per week exercise programme was a combination of aerobic exercise and resistance exercise and was conducted within 2 hours of each session. To the best of our knowledge, this exercise programme was the most suitable exercise training and this was the first time to investigate the effects of intradialytic group exercise on MHD patients.

According to the flow chart of participants (Fig.1), there were 7 patients dropped out for the losing of motivation and sample churn rate for losing of motivation was $7.8 \%$ (7/90). With more exercise programme participants, our study showed a relatively lower sample churn rate compared to former studies about intradialytic exercise in MHD patients[4, 16, 40,46-49]. The exercise culture, which was cultivated by fostering the common identity among participants and increasing social interaction during the group exercise, may be the main reason for the low dropout rate. Health care providers and patients 
may tend to treat exercise as the new "normal" in a physical and social environment, thus limiting opportunities for sedentary behaviors[21].

We used both anthropometric indicators and laboratory indicators to reflect the nutritional state of MHD patients. Our findings on the nutrition indicators confirm that intradialytic group exercise has a positive effect on malnutrition in MHD patients, which are consisted with previous studies[13, 50-52]. Although 3 more patients returned back to normal BMI level at 12 weeks, we found no significant difference in BMI between baseline and 12 weeks post intervention. Following are potential reasons for this result: (1) Our study set the BMI as a categorical variable, thereby patients those lost weight during the intervention but remained in the overweight level at 12 weeks were ignored; (2) The intervention length was not long enough to present a significant difference in BMI. The exercise programme showed a positive effect on other nutrition indications, especially the TSF, MAMC and HGS, with medium to large effect size.

Results also showed that the intradialytic group exercise could improve the QOL of MHD patients gradually. This finding was in consistence with what were found before[53-56]. Survival of MHD patients has been prolonged, but the improvement in quality of life has not keep in pace obviously[57]. Exercise rehabilitation may improve the quality of life in MHD patients by reducing microinflammatory reactions, improving nutritional status, and etc.

Exercise training has been proved to be important to MHD patients. However, it has received limited attention in both MHD patients and health providers for diverse reasons, among which, the fear of injuries, the lack of motivation and resources restrictions are the common barriers[17]. With supervision of medical staff and with the peer support from other patients, intradialytic group exercise seems to provide a way for MHD patients to overcome the fear of injuries and sustain the motivation. Moreover, group exercise provides a resource-saved way of exercise training, because several patients can do exercise under the supervision of a health provider. Based on these findings, MHD patients are encouraged to take intradialytic group exercise which really works in keeping motivation.

\section{Limitations of the study}

Although the study generates some new knowledge in the exercise rehabilitation in MHD patients, there are still some important limitations to note. Firstly, this is a single center study, while results from a multicenter study enrolling more participants may be more reliable. Secondly, this is a single-group repeated-measures design study and studies with a control group (such as randomized controlled trials) are needed to assess the effectiveness of the intradialytic group exercise. Thirdly, a study with longer period is needed to assess longer term health impacts.

\section{Conclusions}

The positive results from this research suggest that intradialytic group exercise programme including aerobic exercise and resistance exercise is a safe and suitable exercise way for maintenance 
hemodialysis patients. This exercise can help keep patients' motivation and improve nutritional status and quality of life in maintenance hemodialysis patients.

\section{Declarations}

\section{Availability of data and materials}

The datasets used and/or analysed during the current study available from the corresponding author on reasonable request and included in the supplementary information files.

\section{Registration}

The study was registered in the Chinese Clinical Trial Registry (ChiCTR2000034394)04/07/2020.

\section{Acknowledgements}

Special thanks go to the healthcare providers in the Hemopurification Center, the Taizhou People's Hospital. We also appreciate all the participations who voluntarily took part in this study.

\section{Funding}

The study was funded by the Taizhou phase V "311 project" through grants RCPY201939. The funders of this study had no role in the study design, collection, analysis and interpretation, writing, or decision to submit the manuscript for publication.

\section{Authors' information}

Affiliations

Nursing Department,Hospital Affiliated 5 to Nantong University(Taizhou People's Hospital), Taizhou, Jiangsu Province, China

Li-Juan Zhou, Li-Yuan Zhang, Dan Shi

Hemodialysis Center,Hospital Affiliated 5 to Nantong University(Taizhou People's Hospital), Taizhou, Jiangsu Province, China

Qian Wang, Li Chen,

\section{Authors' contributions}

Conception and design of the research: Dan Shi, Li-Yuan Zhang, Li-Juan Zhou. Acquisition of data: Qian Wang, Li Chen. Analysis and interpretation of the data: Li-Juan Zhou, Li-Yuan Zhang. Statistical analysis: Li-Yuan Zhang, Li-Juan Zhou. Writing of the manuscript: Li-Yuan Zhang, Li-Juan Zhou. Critical revision of the manuscript for intellectual content: Dan Shi. Each author contributed important intellectual content 
during manuscript drafting or revision and accepts accountability for the overall work by ensuring that questions pertaining to the accuracy or integrity of any portion of the work are appropriately investigated and resolved. The author(s) read and approved the final manuscript.

\section{Corresponding author}

Correspondence to Dan Shi.

\section{Ethics approval and consent to participate}

The study was conducted according to the Declaration of Helsinki and approved by the Ethics Committee of Taizhou People's Hospital, China (KY 202004001). All participants gave informed consent before participation.

\section{Consent for publication}

All authors had approved and gave their consent for submission and publications of this manuscript.

\section{Competing interests}

No, I declare that the authors have no competing interests as defined by BMC, or other interests that might be perceived to influence the results and/or discussion reported in this paper.

\section{References}

1. Zhang L, Wang F, Wang L, Wang W, Liu B, Liu J, Chen M, He Q, Liao Y, Yu X et al: Prevalence of chronic kidney disease in China: a cross-sectional survey. The Lancet 2012, 379(9818):815-822.

2. Liu J, Yu S, Yuan H, Fu P: Current status of exercise rehabilitation in maintenance hemodialysis patients. West China Medical Journal 2020, 35(7):757-761.

3. Kopple JD, Storer T, Casburi R: Impaired exercise capacity and exercise training in maintenance hemodialysis patients. J RENAL NUTR 2005, 15(1):44-48.

4. Cho J, Lee J, Lee S, Park H, Choi S, Kim JC: Effect of intradialytic exercise on daily physical activity and sleep quality in maintenance hemodialysis patients. INT UROL NEPHROL 2018, 50(4):745754.

5. Ortiz A, Covic A, Fliser D, Fouque D, Goldsmith D, Kanbay M, Mallamaci F, Massy ZA, Rossignol P, Vanholder $\mathrm{R}$ et al: Epidemiology, contributors to, and clinical trials of mortality risk in chronic kidney failure. LANCET 2014, 383(9931):1831-1843.

6. Peng Y, Chiang C, Hung K, Chang C, Lin C, Yang C, Chen T, Hsia C, Chen D, Hsu W et al: Are Both Psychological and Physical Dimensions in Health-Related Quality of Life Associated with Mortality in Hemodialysis Patients: A 7-Year Taiwan Cohort Study. BLOOD PURIFICAT 2010, 30(2):98-105. 
$\mathrm{SH}$, Rayner $\mathrm{HC}$ et al: Associations of self-reported physical activity types and levels with quality of life, depression symptoms, and mortality in hemodialysis patients: the DOPPS. CLIN J AM SOC NEPHRO 2014, 9(10):1702-1712.

8. $\mathrm{K} \mathrm{DOQI} \mathrm{Workgroup} \mathrm{<:} \mathrm{K/DOQI} \mathrm{clinical} \mathrm{practice} \mathrm{guidelines} \mathrm{for} \mathrm{cardiovascular} \mathrm{disease} \mathrm{in} \mathrm{dialysis}$ patients. Am. J. Kidney Dis 2005, 45(4 Suppl. 3).

9. Smith AC, Burton JO: Exercise in kidney disease and diabetes: time for action. Journal of renal care 2012, 38 Suppl 1:52-58.

10. Suh MR, Jung HH, Kim SB, Park JS, Yang WS: Effects of regular exercise on anxiety, depression, and quality of life in maintenance hemodialysis patients. Ren Fail 2002, 24(3):337-345.

11. Kutner NG, Zhang R, Huang Y, Kaysen GA, Park J: Lower C-reactive protein and better hemodialysis survival are associated with regular exercise activity: Longitudinal outcomes from the ACTIVE-ADIPOSE special study. HEMODIAL INT 2016, 20(3):473-483.

12. Heiwe S, Jacobson SH: Exercise Training in Adults With CKD: A Systematic Review and Metaanalysis. AM J KIDNEY DIS 2014, 64(3):383-393.

13. Suhardjono, Umami V, Tedjasukmana D, Setiati S: The effect of intradialytic exercise twice a week on the physical capacity, inflammation, and nutritional status of dialysis patients: A randomized controlled trial. HEMODIAL INT 2019, 23(4):486-493.

14. Pu J, Jiang Z, Wu W, Li L, Zhang L, Li Y, Liu Q, Ou S: Efficacy and safety of intradialytic exercise in haemodialysis patients: a systematic review and meta-analysis. BMJ OPEN 2019, 9(1):e20633.

15. Jung T, Park S: Intradialytic Exercise Programs for Hemodialysis Patients. Chonnam Medical Journal 2011, 47(2):61.

16. Dong Z, Zhang H, Yin L: Effects of intradialytic resistance exercise on systemic inflammation in maintenance hemodialysis patients with sarcopenia: a randomized controlled trial. INT UROL NEPHROL 2019, 51(8):1415-1424.

17. Tao X, Chow SKY, Wong FKY: A nurse-led case management program on home exercise training for hemodialysis patients: A randomized controlled trial. INT J NURS STUD 2015, 52(6):1029-1041.

18. Tsutsumimoto K, Doi T, Shimada H, Makizako H, Suzuki T: Effects of group exercise programmes on quality of life in older adults with mild cognitive impairment: preliminary results from a randomized controlled trial. PSYCHOGERIATRICS 2016, 16(5):327-328.

19. Taraldsen K, Boulton E, Helbostad JL, Saltvedt I, Granbo R: Client, caregiver, volunteer, and therapist views on a voluntary supported group exercise programme for older adults with dementia. $B M C$ 
20. Jhamb M, McNulty ML, Ingalsbe G, Childers JW, Schell J, Conroy MB, Forman DE, Hergenroeder A, Dew MA: Knowledge, barriers and facilitators of exercise in dialysis patients: a qualitative study of patients, staff and nephrologists. BMC NEPHROL 2016, 17.

21. Clarke $A L$, Jhamb M, Bennett PN: Barriers and facilitators for engagement and implementation of exercise in end-stage kidney disease: Future theory-based interventions using the Behavior Change Wheel. SEMIN DIALYSIS 2019, 32(4):308-319.

22. Assawasaksakul N, Sirichana W, Joosri W, Kulaputana O, Eksakulkla S, Ketanun C, Kittiskulnam $\mathrm{P}$, Chantadisai M, Takkavatakarn K, Susantitaphong $\mathrm{P}$ et al: Effects of intradialytic cycling exercise on daily physical activity, physical fitness, body composition, and clinical parameters in high-volume online hemodiafiltration patients: a pilot randomized-controlled trial. INT UROL NEPHROL 2021, 53(2):359-371.

23. Martins Do Valle F, Valle Pinheiro B, Almeida Barros AA, Ferreira Mendonça W, de Oliveira AC, de Oliveira Werneck G, de Paula RB, Moura Reboredo M: Effects of intradialytic resistance training on physical activity in daily life, muscle strength, physical capacity and quality of life in hemodialysis patients: a randomized clinical trial. DISABIL REHABIL 2020, 42(25):3638-3644.

24. Arney BE, Glover R, Fusco A, Cortis C, de Koning JJ, van Erp T, Jaime S, Mikat RP, Porcari JP, Foster C: COMPARISON OF RATING OF PERCEIVED EXERTION SCALES DURING INCREMENTAL AND INTERVAL EXERCISE. KINESIOLOGY 2019, 51(2):150-157.

25. Ben-Menachem E: Clinical guidelines on the identification, evaluation, and treatment of overweight and obesity in adults: The evidence report. EPILEPSIA 2007, 48:42-45.

26. He L, Yang N, Wang J, Huang J, Li W, Xu L, Ping F, Li Y, Zhang H: Mid-Arm Muscle and Subcutaneous Fat Associated with All-Cause Mortality Independent of BMI: A Prospective Cohort Study. OBESITY 2021, 29(7):1203-1214.

27. Huang CX, Tighiouart H, Dwyer JT, Levey AS, Sarnak MJ, Beddhu S, Cheung AK, Eknoyan G, Beck GJ: Both low muscle mass and low fat are associated with higher all-cause mortality in hemodialysis patients. KIDNEY INT 2010, 77(7):624-629.

28. Ikizler TA, Cuppari L: The $\mathbf{2 0 2 0}$ Updated KDOQI Clinical Practice Guidelines for Nutrition in Chronic Kidney Disease. BLOOD PURIFICAT 2021, 50(4-5):667-671.

29. Tao X, Chow SKY, Wong FKY: Determining the validity and reliability of the Chinese version of the Kidney Disease Quality of Life Questionnaire (KDQOL-36 ${ }^{\mathrm{m}}$ ). BMC NEPHROL 2014, 15(1):115.

30. Ron D. Hays JKDM: Kidney Disease Quality of Life Short Form (KDQOL-SFTM), Version 1.3: A Manual for Use and Scoring. In., vol. 2021; 1997. 
31. Suhardjono, Umami V, Tedjasukmana D, Setiati S: The effect of intradialytic exercise twice a week on the physical capacity, inflammation, and nutritional status of dialysis patients: A randomized controlled trial. HEMODIAL INT 2019, 23(4):486-493.

32. Henrique D, Reboredo MD, Chaoubah A, de Paula RB: Aerobic Exercise Improves Physical Capacity in Patients under Chronic Hemodialysis. ARQ BRAS CARDIOL 2010, 94(6):823-828.

33. Afshar R, Emany A, Saremi A, Shavandi N, Sanavi S: Effects of Intradialytic Aerobic Training on Sleep Quality in Hemodialysis Patients. IRAN J KIDNEY DIS 2011, 5(2):119-123.

34. Salhab N, Karavetian M, Kooman J, Fiaccadori E, El Khoury CF: Effects of intradialytic aerobic exercise on hemodialysis patients: a systematic review and meta-analysis. J NEPHROL 2019, 32(4):549566.

35. Segura-Orti E, Kouidi E, Lison JF: Effect of resistance exercise during hemodialysis on physical function and quality of life: randomized controlled trial. CLIN NEPHROL 2009, 71(5):527-537.

36. Bullani R, El-Housseini Y, Giordano F, Larcinese A, Ciutto L, Bertrand PC, Wuerzner G, Burnier M, Teta D: Effect of Intradialytic Resistance Band Exercise on Physical Function in Patients on Maintenance Hemodialysis: A Pilot Study. J RENAL NUTR 2011, 21(1):61-65.

37. Saitoh M, Ogawa M, Dos Santos MR, Kondo H, Suga K, Itoh H, Tabata Y: Effects of Intradialytic Resistance Exercise on Protein Energy Wasting, Physical Performance and Physical Activity in Ambulatory Patients on Dialysis: A Single-Center Preliminary Study in a Japanese Dialysis Facility. THER APHER DIAL 2016, 20(6):632-638.

38. Olvera-Soto MG, Valdez-Ortiz R, Alvarenga J, Espinosa-Cuevas MD: Effect of Resistance Exercises on the Indicators of Muscle Reserves and Handgrip Strength in Adult Patients on Hemodialysis. J RENAL NUTR2016, 26(1):53-60.

39. Moriyama Y, Hara M, Aratani S, Ishikawa H, Kono K, Tamaki M: The association between six month intra-dialytic resistance training and muscle strength or physical performance in patients with maintenance hemodialysis: a multicenter retrospective observational study. BMC NEPHROL 2019, 20.

40. Do Valle FM, Pinheiro BV, Barros A, Mendonca WF, de Oliveira AC, Werneck GD, de Paula RB, Reboredo MM: Effects of intradialytic resistance training on physical activity in daily life, muscle strength, physical capacity and quality of life in hemodialysis patients: a randomized clinical trial. DISABIL REHABIL 2020, 42(25):3638-3644.

41. Bogataj ', Pajek M, Pajek J, Buturović Ponikvar J, Paravlic AH: Exercise-Based Interventions in Hemodialysis Patients: A Systematic Review with a Meta-Analysis of Randomized Controlled Trials. $J$ CLIN MED 2020, 9(1):43. 
42. Parker $\mathrm{K}$ : Intradialytic Exercise is Medicine for Hemodialysis Patients. CURR SPORT MED REP 2016, 15(4):269-275.

43. Sheng KX, Zhang P, Chen LL, Cheng J, Wu CC, Chen JH: Intradialytic Exercise in Hemodialysis Patients: A Systematic Review and Meta-Analysis. AM J NEPHROL 2014, 40(5):478-490.

44. Kontos PC, Miller KL, Brooks D, Jassal SV, Spanjevic L, Devins GM, De Souza MJ, Heck C, Laprade J, Naglie G: Factors influencing exercise participation by older adults requiring chronic hemodialysis: a qualitative study. INT UROL NEPHROL 2007, 39(4):1303-1311.

45. Nonoyama ML, Brooks D, Ponikvar A, Jassal SV, Kontos P, Devins GM, Spanjevic L, Heck C, Laprade J, Naglie G: Exercise program to enhance physical performance and quality of life of older hemodialysis patients: a feasibility study. INT UROL NEPHROL 2010, 42(4):1125-1130.

46. Lopes LCC, Mota JF, Prestes J, Schincaglia RM, Silva DM, Queiroz NP, Freitas ATVD, Lira FS, Peixoto MDRG: Intradialytic Resistance Training Improves Functional Capacity and Lean Mass Gain in Individuals on Hemodialysis: A Randomized Pilot Trial. ARCH PHYS MED REHAB 2019, 100(11):21512158.

47. Jeong JH, Biruete A, Fernhall B, Wilund KR: Effects of acute intradialytic exercise on cardiovascular responses in hemodialysis patients. HEMODIAL INT 2018, 22(4):524-533.

48. Rhee SY, Song JK, Hong SC, Choi JW, Jeon HJ, Shin DH, Ji EH, Choi EH, Lee J, Kim A et al: Intradialytic exercise improves physical function and reduces intradialytic hypotension and depression in hemodialysis patients. KOREAN J INTERN MED 2019, 34(3):588-598.

49. Cheng YJ, Zhao XJ, Zeng W, Xu MC, Ma YC, Wang M: Effect of Intradialytic Exercise on Physical Performance and Cardiovascular Risk Factors in Patients Receiving Maintenance Hemodialysis: A Pilot and Feasibility Study. BLOOD PURIFICAT 2020, 49(4):409-418.

50. Saitoh M, Ogawa M, Dos Santos MR, Kondo H, Suga K, Itoh H, Tabata Y: Effects of Intradialytic Resistance Exercise on Protein Energy Wasting, Physical Performance and Physical Activity in Ambulatory Patients on Dialysis: A Single-Center Preliminary Study in a Japanese Dialysis Facility. THER APHER DIAL 2016, 20(6):632-638.

51. Liao MT, Liu WC, Lin FH, Huang CF, Chen SY, Liu CC, Lin SH, Lu KC, Wu CC: Intradialytic aerobic cycling exercise alleviates inflammation and improves endothelial progenitor cell count and bone density in hemodialysis patients. MEDICINE 2016, 95(27).

52. Salhab N, Alrukhaimi M, Kooman J, Fiaccadori E, Aljubori H, Rizk R, Karavetian M: Effect of Intradialytic Exercise on Hyperphosphatemia and Malnutrition. NUTRIENTS 2019, 11(10).

53. Rochmawati E, Utomo EK, Makiyah S: Improving dialysis adequacy and quality of life in patients undergoing hemodialysis with twice a week range of motion exercise. THER APHER DIAL 2021. 
54. Warsame F, Ying H, Haugen CE, Thomas AG, Crews DC, Shafi T, Jaar B, Chu NM, Segev DL, McAdams-DeMarco MA: Intradialytic Activities and Health-Related Quality of Life Among Hemodialysis Patients. AM J NEPHROL 2018, 48(3):181-189.

55. Zhang F, Huang LY, Wang WQ, Shen QY, Zhang HC: Effect of intradialytic progressive resistance exercise on physical fitness and quality of life in maintenance haemodialysis patients. NURSING OPEN 2020, 7(6):1945-1953.

56. Zhang F, Zhou WQ, Sun QZ, Zhai YY, Zhang Y, Su H, Wang ZC: Effects of intradialytic resistance exercises on physical performance, nutrient intake and quality of life among haemodialysis people: A systematic review and meta-analysis. NURSING OPEN 2021, 8(2):529-538.

57. Levin A, Tonelli M, Bonventre J, Coresh J, Donner JA, Fogo AB, Fox CS, Gansevoort RT, Heerspink $\mathrm{H}$, Jardine $\mathrm{M}$ et al: Global kidney health 2017 and beyond: a roadmap for closing gaps in care, research, and policy. LANCET 2017, 390(10105):1888-1917.

\section{Figures}

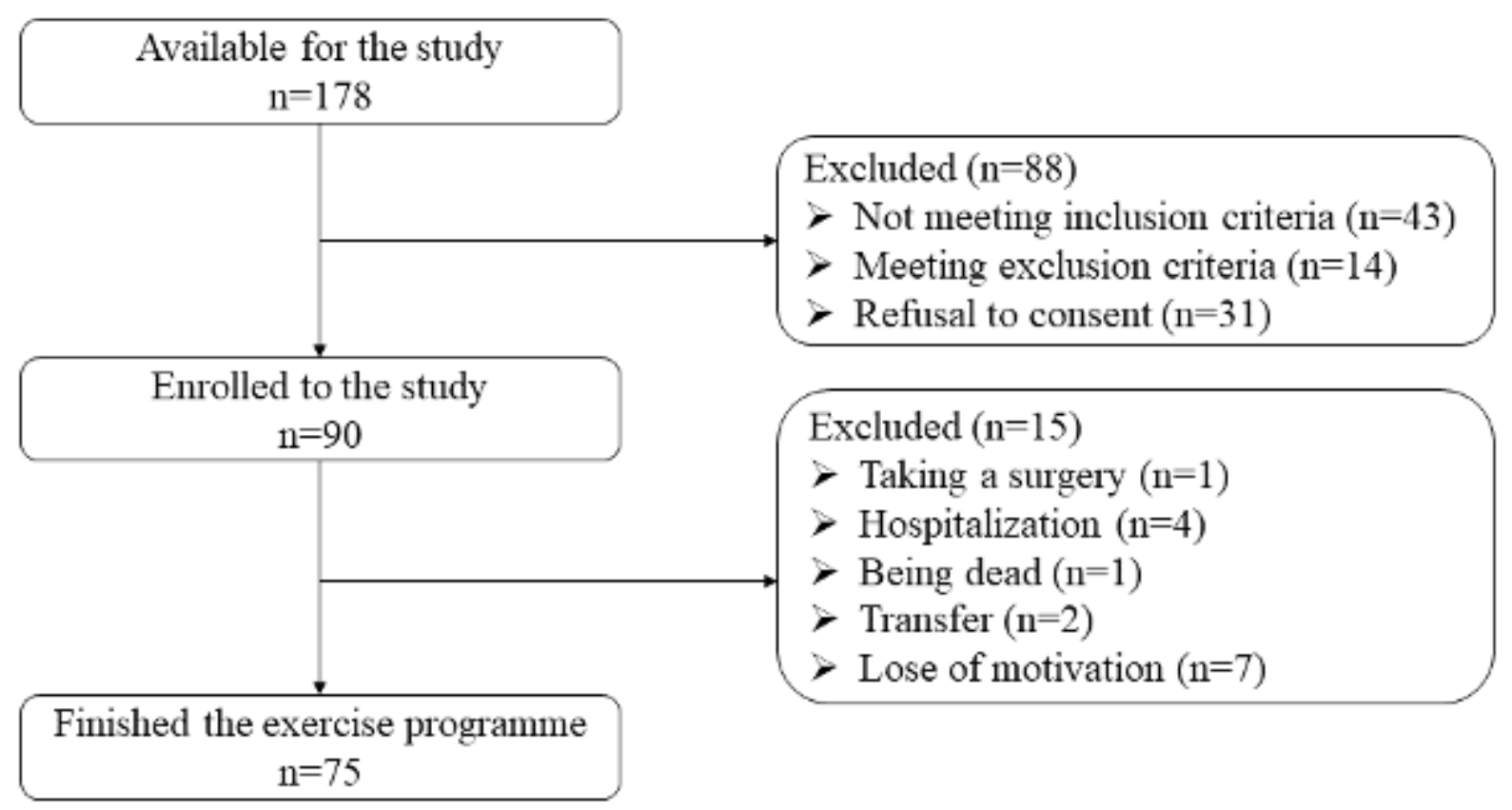

Figure 1

Flow chart of participants

\section{Supplementary Files}

This is a list of supplementary files associated with this preprint. Click to download. 
- Ethicalproof.jpeg

Page 20/20 